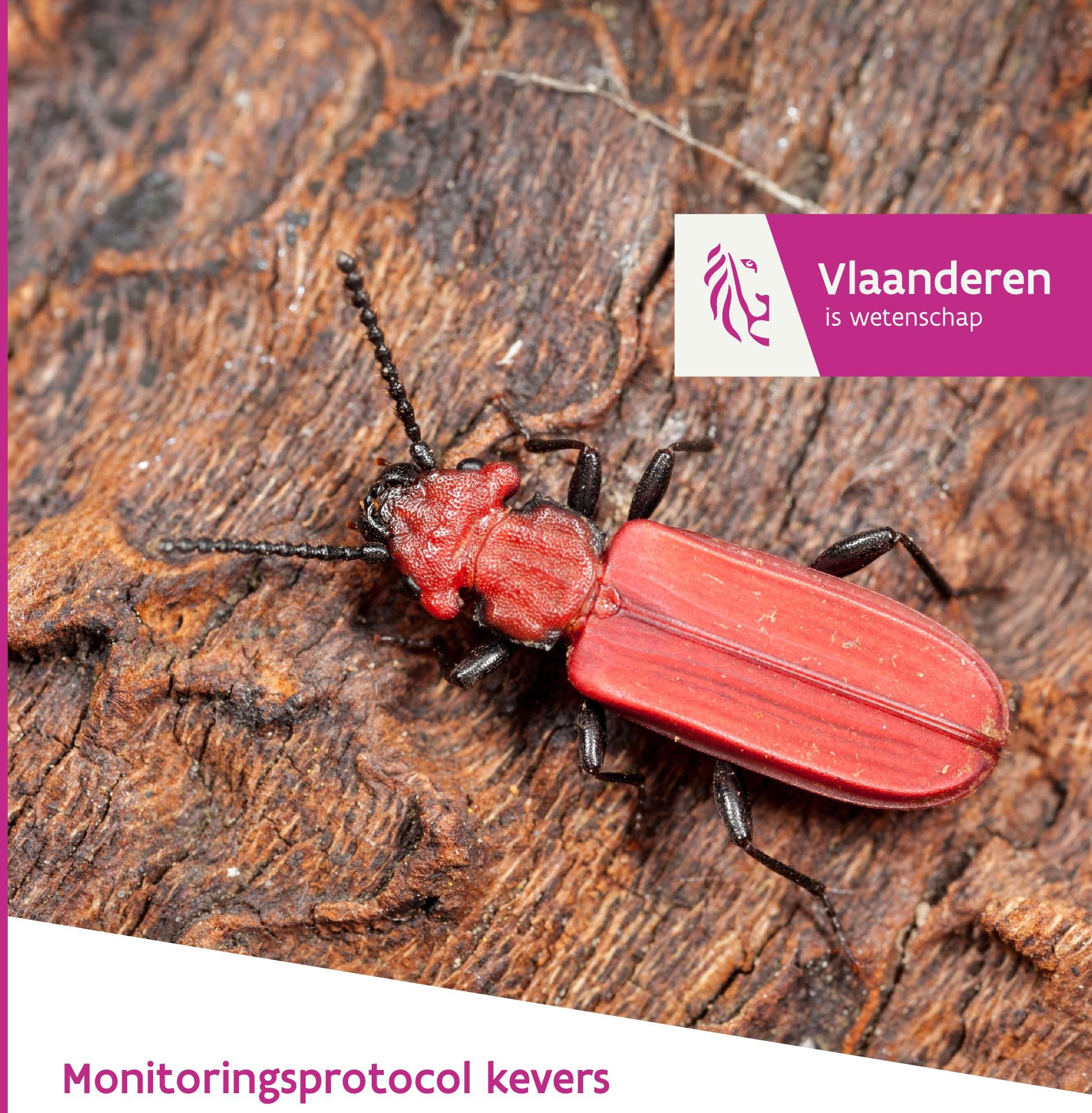

Versie 2.0

Arno Thomaes, Hannes Ledegen, Toon Westra

INSTITUUT

NATUUR- EN BOSONDERZOEK 


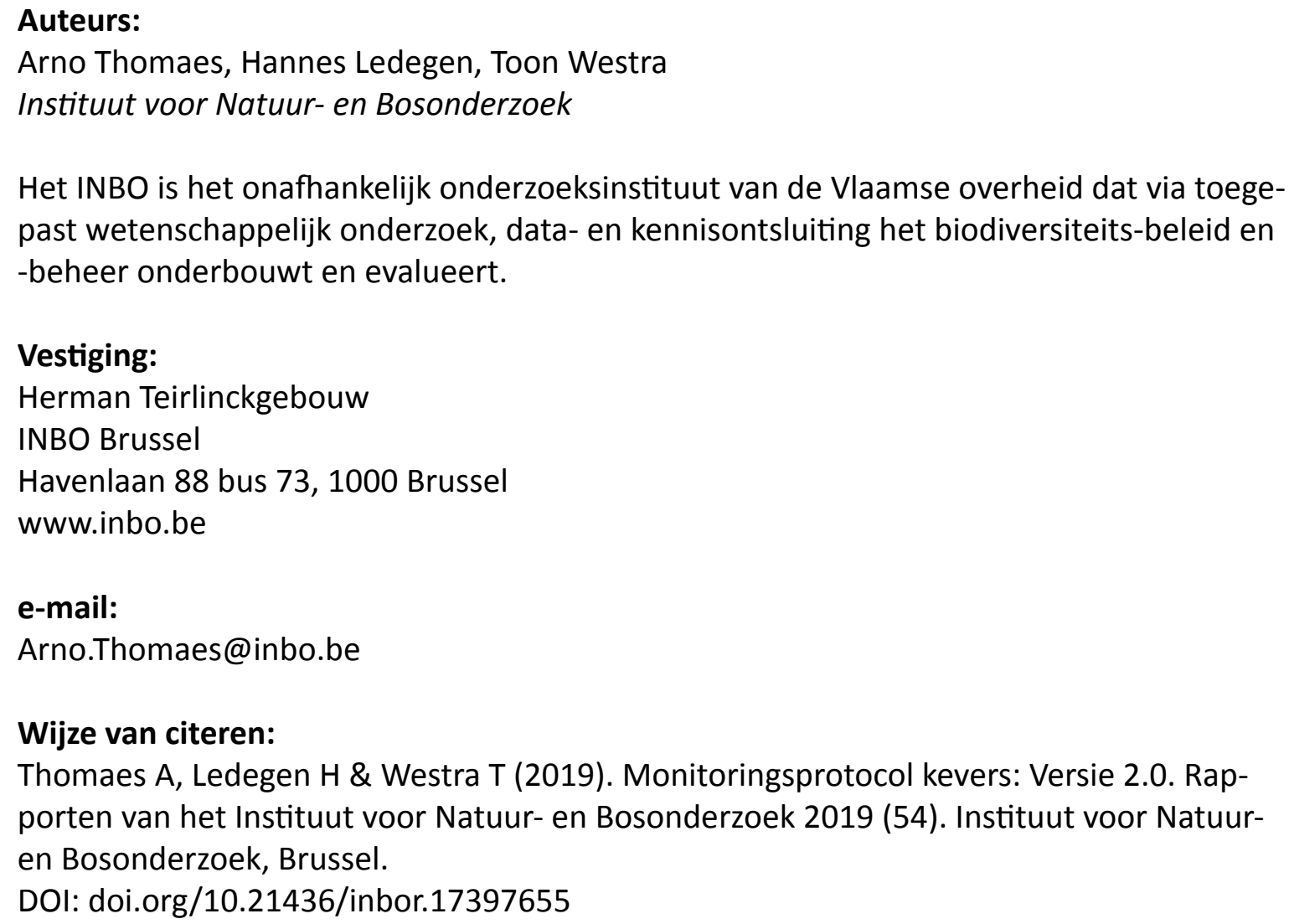

(C) 2019, Instituut voor Natuur- en Bosonderzoek 
INSTITUUT

NATUUR- EN

BOSONDERZOEK

\title{
MONITORINGSPROTOCOL KEVERS
}

\author{
Versie $\mathbf{2 . 0}$
}

Arno Thomaes, Hannes Ledegen \& Toon Westra

doi.org/10.21436/inbor.17397655

Rapporten van het Instituut voor Natuur- en Bosonderzoek 2019 (54) 


\section{Dankwoord}

In de eerste plaats bedanken we Natuurpunt voor het ter beschikking stellen van de waarnemingen van kevers uit www.waarnemingen.be om zo de beste locaties te kunnen achterhalen voor het monitoringmeetnet. Daarnaast bedanken we ook de talloze waarnemers en validatoren die deze gegevens verzamelden, meehielpen aan inhaalslagen en gegevens valideerden alsook vrijwilligers die meehielpen om een deel van deze monitoring uit te testen. Voorwoord

Om op een onderbouwde manier te kunnen rapporteren over de verspreiding en trend van Vlaams prioritaire soorten en Europese Habitat- en Vogelrichtlijnsoorten is er nood aan een wetenschappelijk en statistisch onderbouwd monitoringnetwerk. Steunend op de eerder gepubliceerde blauwdrukken voor de soortenmonitoring in Vlaanderen (De Knijf et al., 2014), werken we hier monitoringmethoden uit en bepalen we het aantal en de selectie van de te monitoren locaties voor kevers. Dit monitoringsprotocol stelde de veldwerkcoördinator in staat om het meetnet op te zetten en te starten met de monitoring. In dit eerste rapport (Thomaes et al., 2016a) stelden we twee protocollen voor om de verspreiding van die soorten via een inhaalslag verder in kaart te brengen. Voor Vliegend hert kan gesteld worden dat de inhaalslag afgerond is, al zullen er steeds nieuwe te onderzoeken waarnemingen opduiken. Bij deze soort kan de aandacht verschoven worden naar de monitoring die al binnen een Europees kader werd opgestart. Voor Roestbruine kniptor werd de voorbije jaren vooral gewerkt aan het wegwerken van praktische problemen (beschikbaarheid van feromonen) en methodologisch onderzoek. Hierdoor is er wel een toegenomen kennis over de verspreiding maar moet een gedegen inhaalslag de komende jaren nog uitgevoerd worden op basis van de hier gespecificeerde methodologie. Tenslotte dook Vermiljoenkever in 2014 op als nieuwe habitatrichtlijnsoort in Vlaanderen. Voor deze soort werd reeds een protocol geschreven (Thomaes \& Marschand, 2019) voor de opvolging en monitoring van de soort. 


\section{Samenvatting}

Dit rapport beschrijft het protocol voor het monitoringmeetnet van de kevers. We sommen de soorten op die gemonitord moeten worden en op welke manier dat moet gebeuren. Voor elke soort is er een individuele methode ontwikkeld. Voor Roestbruine kniptor moet de inhaalslag verder afgewerkt worden met feromoonvallen alvorens een monitoring opgestart kan worden. Bij Vliegend hert kan gestart worden met transectmonitoring, een methode die al opgestart is in het kader van een Europees project. Voor Vermiljoenkever, tenslotte, kan er gestart worden aan een inhaalslag door naar de larven te zoeken.

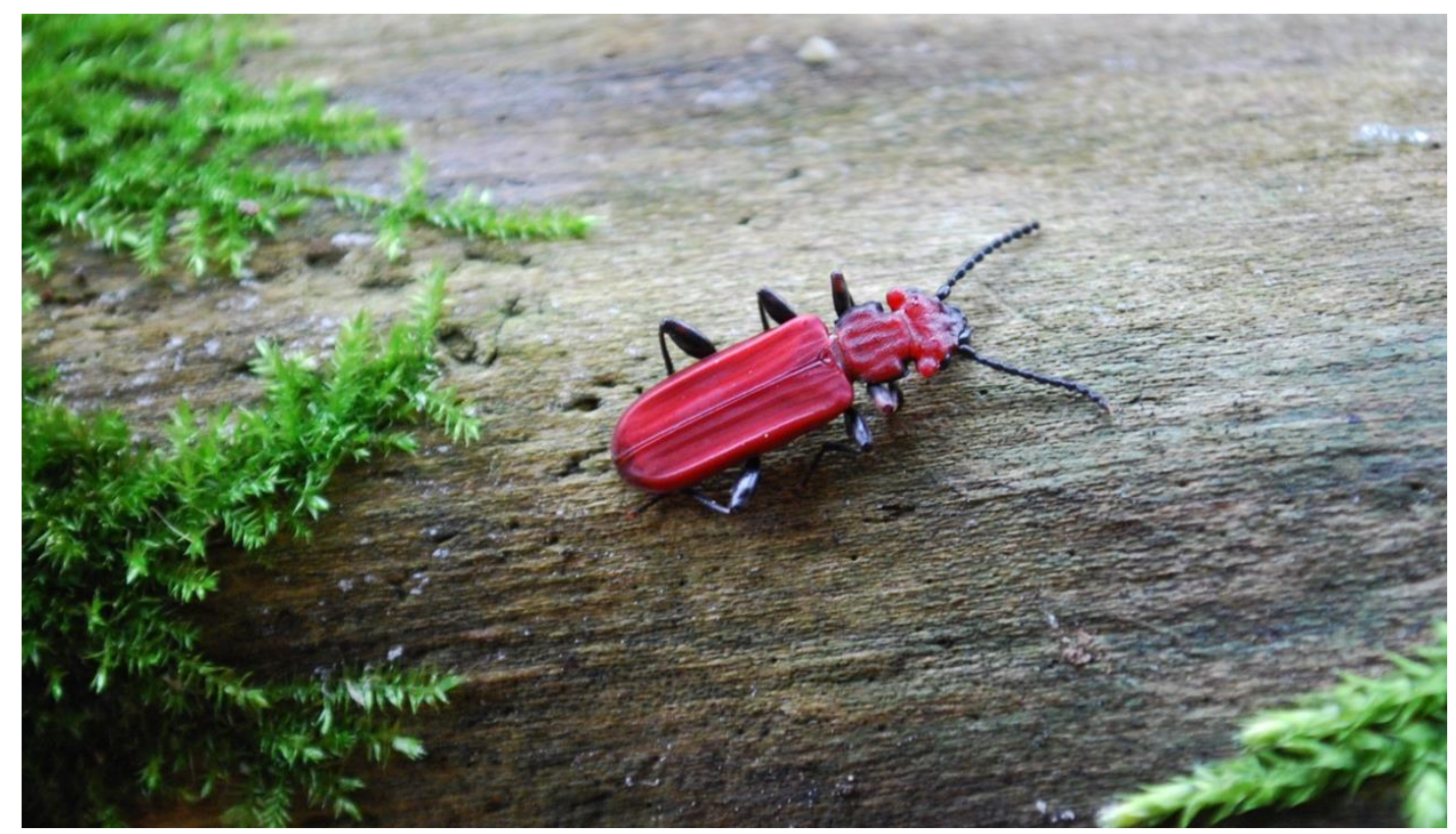

Figur 1 Vermiljoenkever, een nieuwe habitatrichtlijnsoort in Vlaanderen (Luc De Keersmaeker)

\section{English abstract}

This report describes the protocol for the beetle monitoring network. We list the species that need to be monitored and the methods to do so. For each species a specific method has been developed. For the Rusty click beetle (Elater ferrugineus), the distribution map needs to be completed first by using pheromone traps. Afterwards the monitoring can be started. For the European stag beetle (Lucanus cervus), we can start the transect monitoring, a method which is already started up for a European project. Finally, for the Red flat bark beetle (Cucujus cinnaberinus) it is possible to commence mapping the distribution by searching for the larvae. 


\section{Inhoudstafel}

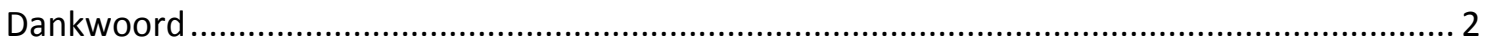

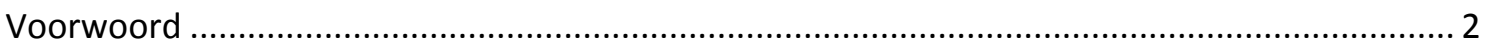

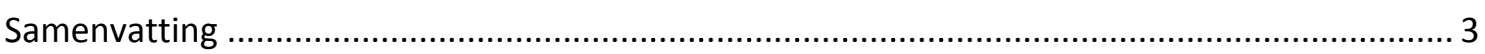

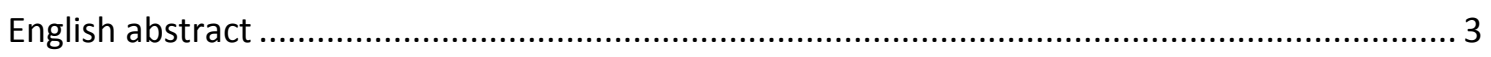

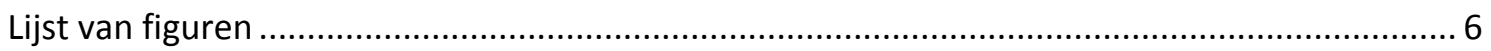

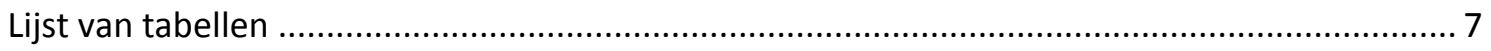

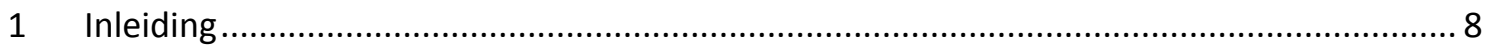

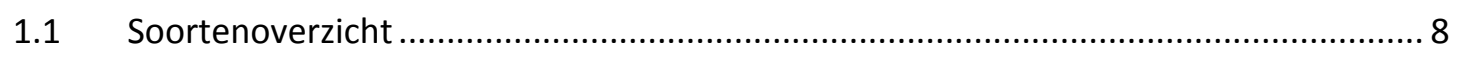

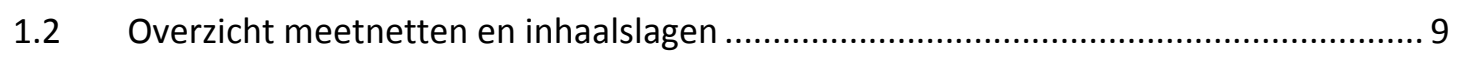

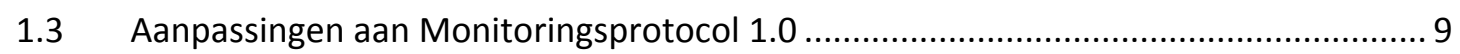

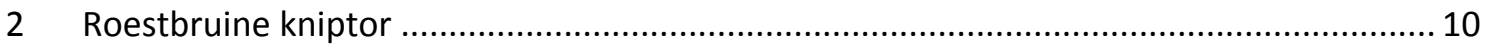

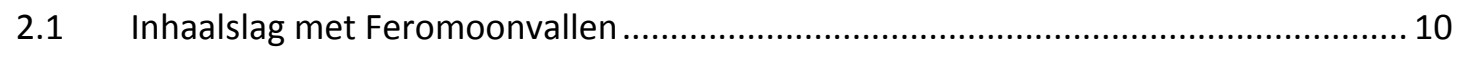

2.1.1 Selectie en prioritering van te onderzoeken hokken ....................................... 10

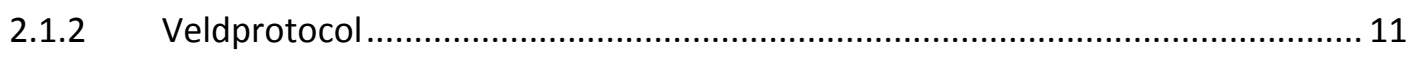

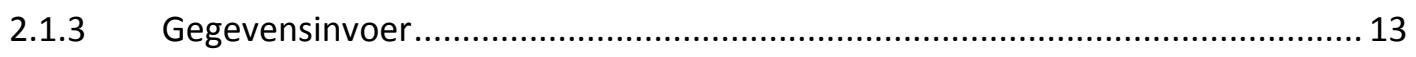

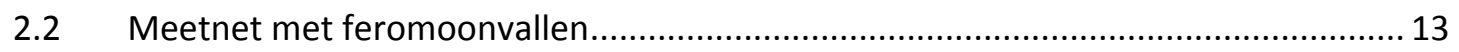

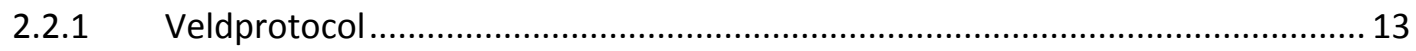

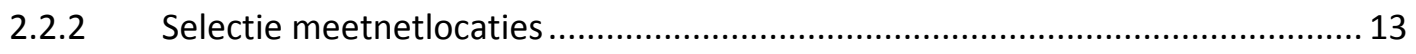

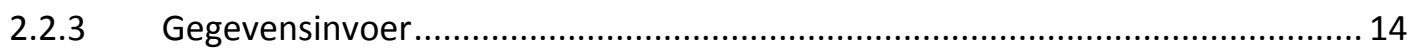

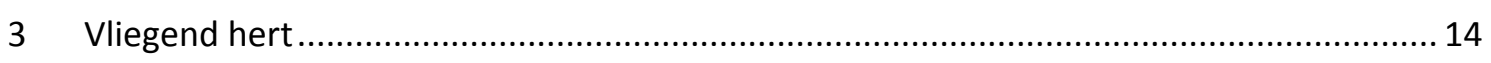

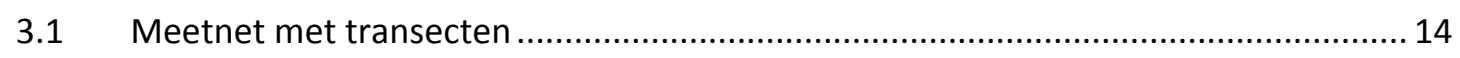

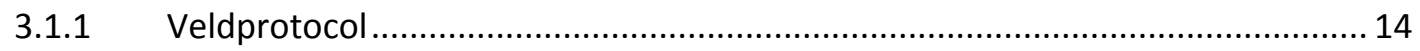

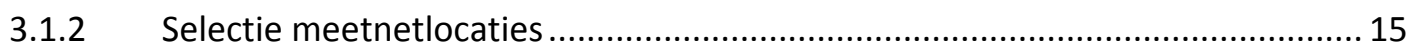

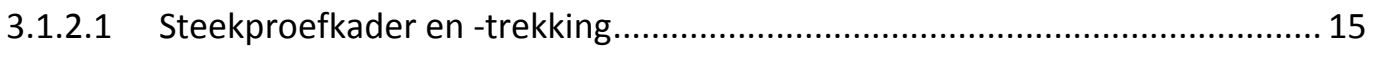

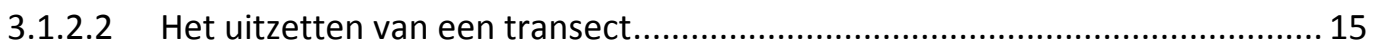

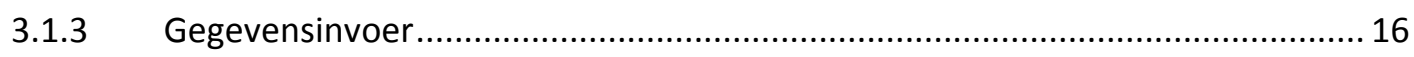


4.1 Inhaalslag met inventarisaties van dode bomen ........................................... 16

4.1.1 Selectie en prioritering van te onderzoeken hokken .................................... 16

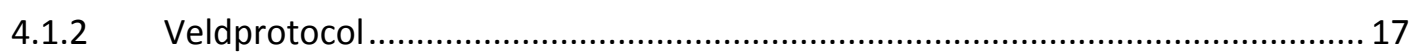

4.1.3 Gegevensinvoer........................................................................ 19

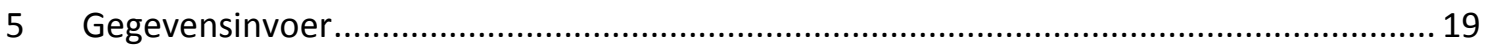

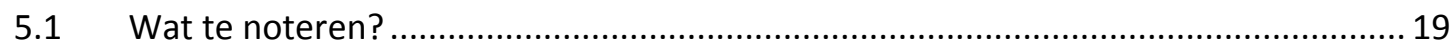

5.1.1 Feromoonvallen (voor inhaalslag of monitoring) ....................................... 19

5.1.2 Transecttellingen ............................................................................. 20

Inventarisaties van dode bomen ............................................................ 20

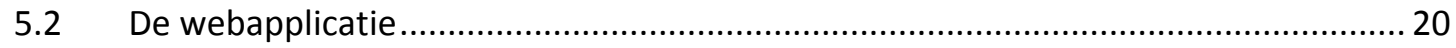

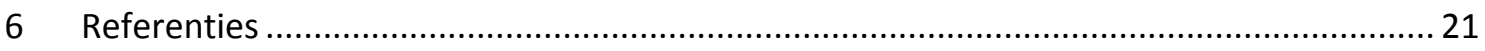

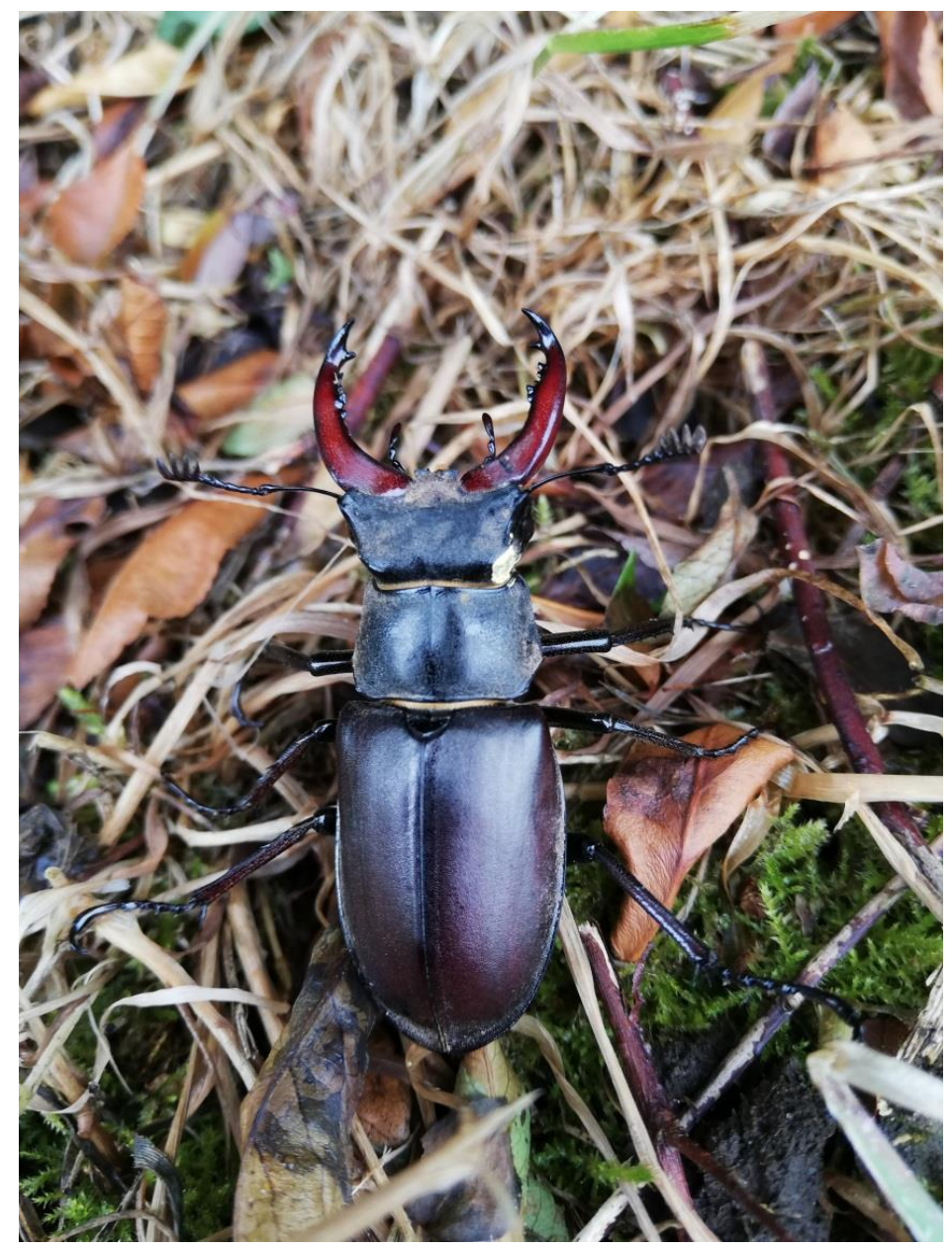

Figuur 2 Vliegend hert (Arianna Tagliani) 


\section{Lijst van figuren}

Figuur 1 Vermiljoenkever, een nieuwe habitatrichtlijnsoort in Vlaanderen....................... 3

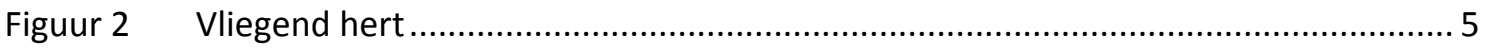

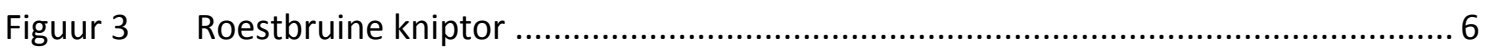

Figuur 4 Hokkenkaart (UTM 1*1 km) met de gekende vindplaatsen 2010-2019 (groen), bevestigde afwezigheden (rood) en te onderzoeken hokken (blauw)

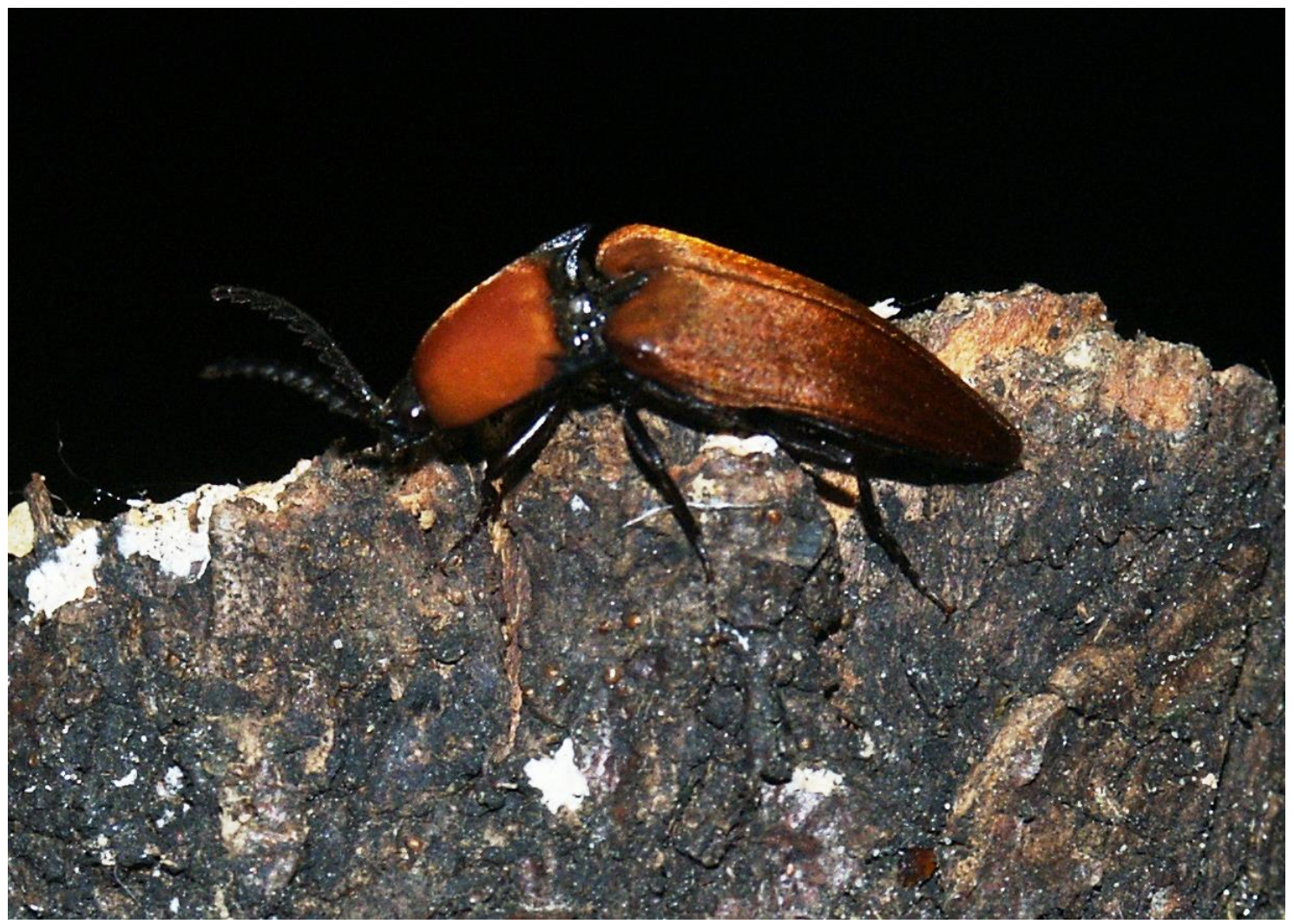

Figuur 3 Roestbruine kniptor (Arno Thomaes) 


\section{Lijst van tabellen}

Tabel 1 Lijst van de Vlaams (VPS) en Europees prioritaire soorten (EPS, HRL II = de soort staat op Annex II van de Habitatrichtlijn, HRL IV = de soort staat op Annex IV van de Habitatrichtlijn) en de aanduiding of er een meetnet voor bestaat in Vlaanderen. De status van Juchtleerkever en Vliegend hert is gebaseerd op de Rode Lijst voor andere soorten NB: niet bepaald of uitgestorven.

Tabel 2 Overzicht van de te monitoren kevers met het jaar waarin de monitoring opgestart werd, het veldprotocol (inv.: inventarisatie van), het type monitoring (pot.: potentieel), het aantal te onderzoeken locaties (\#loc, 1x1km utm hokken), de cyclus waarmee de locaties bezocht worden en het aantal bezoeken per jaar en per locatie (\#bez). ...................................... 9

Tabel 3 Lijst met te onderzoeken kilometerhokken voor de Roestbruine kniptor.................. 11

Tabel 4 Lijst met te onderzoeken kilometerhokken voor Vermiljoenkever ............................. 18 


\section{INLEIDING}

Voor de ondersteuning van het Vlaamse en Europese natuurbeleid is onderbouwde informatie nodig over de verspreiding en de trends van Vlaams en Europees prioritaire soorten (Adriaens et al., 2011). Om deze informatie zo efficiënt mogelijk in te zamelen en te verwerken, is een goede samenwerking tussen vrijwilligers en natuurverenigingen enerzijds en professionelen anderzijds essentieel (Herremans et al., 2014). Methoden die hierbij gebruikt worden, werden in De Knijf et al. (2014) als blauwdrukken ontwikkeld voor het opvolgen van Vlaams prioritaire en Europese Natura 2000-soorten. Voor de gegevensinzameling werken we ook zo conform mogelijk aan internationale standaarden om een maximale vergelijkbaarheid te realiseren. Een monitoringsprotocol geeft een meer gedetailleerde en praktische invulling van de algemene principes in de blauwdruk. Een eerste versie van het monitoringsprotocol kevers (Thomaes et al., 2016a) vormde de basis voor de opstart van de verschillende inhaalslagen in de periode 2016-2019. Gezien het afronden van deze inhaalslagen en op basis van de opgedane ervaring bij het veldwerk in deze opstartfase, wordt nu een nieuwe versie (versie 2.0) van het monitoringsprotocol kevers voorgesteld. Verder werd ook Vermiljoenkever aan de lijst toegevoegd als nieuwe habitatrichtlijnsoort in Vlaanderen. In de opstartfase van de meetnetten werden ook het invoerportaal www.meetnetten.be en de mobiele meetnettenapplicatie verder ontwikkeld. De informatie hierover in de eerste versie van het montoringsprotocol werd daarom ook geactualiseerd.

\subsection{SOORTENOVERZICHT}

In Tabel 1 geven we een overzicht van de Vlaams en Europees prioritaire kevers. Voor habitatrichtlijnsoort Juchtleerkever werd geen monitoring voorzien aangezien er actueel geen populaties bekend zijn, een inhaalslag loopt voor deze soort door middel van een snuffelhond. 
Tabel 1 Lijst van de Vlaams (VPS) en Europees prioritaire soorten (EPS, HRL II = de soort staat op Annex II van de Habitatrichtlijn, HRL IV = de soort staat op Annex IV van de Habitatrichtlijn) en de aanduiding of er een meetnet voor bestaat in Vlaanderen. De status van Juchtleerkever en Vliegend hert is gebaseerd op de Rode Lijst voor andere soorten NB: niet bepaald of uitgestorven.

\begin{tabular}{lcccc}
$\begin{array}{l}\text { Nederlandse naam } \\
\text { Kevers }\end{array}$ & Wetenschappelijke naam & Type & Status & Meetnet \\
\hline & & & \\
Juchtleerkever & Osmoderma eremita & EPS (HRL II) & Ernstig bedreigd & + \\
Roestbruine kniptor & Elater ferrugineus & VPS* & NB & + \\
Vermiljoenkever & Cucujus cinnaberinus & EPS (HRL II) & NB & + \\
Vliegend hert & Lucanus cervus & EPS (HRL II) & Bedreigd & + \\
\hline
\end{tabular}

*: Deze soort vervangt Gouden tor uit de orginele VPS (Thomaes et al., 2016b).

\subsection{OVERZICHT MEETNETTEN EN INHAALSLAGEN}

In Tabel 2 geven we een overzicht van de soorten die opgevolgd moeten worden samen met het jaar waarin de monitoring opgestart werd, het veldprotocol, het type monitoring, het aantal te onderzoeken locaties, de cyclus waarmee de locaties bezocht worden en het aantal bezoeken dat per jaar op elke locatie gedaan moet worden.

Tabel 2 Overzicht van de te monitoren kevers met het jaar waarin de monitoring opgestart werd, het veldprotocol (inv.: inventarisatie van), het type monitoring (pot.: potentieel), het aantal te onderzoeken locaties (\#loc, $1 \times 1 \mathrm{~km}$ utm hokken), de cyclus waarmee de locaties bezocht worden en het aantal bezoeken per jaar en per locatie (\#bez).

\begin{tabular}{|c|c|c|c|c|c|c|}
\hline $\begin{array}{l}\text { Nederlandse naam } \\
\text { Inhaalslag }\end{array}$ & Opstartjaar & Protocol & Type & $\#$ \#loc & Cyclus & \#bez \\
\hline Roestbruine kniptor & 2017 & feromoonvallen & pot. leefgebied & 83 & eenmalig & 3 \\
\hline $\begin{array}{l}\text { Vermiljoenkever } \\
\text { Meetnet }\end{array}$ & 2019 & inv. dode bomen & pot. leefgebied & 30 & 3-jaarlijks & 1 \\
\hline Roestbruine kniptor & te bepalen & feromoonvallen & steekproef & 30 & 3-jaarlijks & 5 \\
\hline Vliegend hert & 2013 & transecten & Integraal & 18 & Jaarlijks & $5-8$ \\
\hline
\end{tabular}

\subsection{AANPASSINGENAAN MONITORINGSPROTOCOL 1.0}

De inhaalslag van Vliegend hert uit het vorige monitoringsprotocol (Thomaes et al., 2016a) is afgerond. In het huidige monitoringsprotocol beschrijven we het meetnet voor deze soort. Voor Roestbruine kniptor is de inhaalslag aangepast op basis van de nieuw verzamelde verspreidingsgegevens en werd een ontwerp voor een meetnet toegevoegd. Voor Vermiljoenkever werd begin 2019 al een protocol voor opvolging (gezien de sterke uitbreiding van de soort) en monitoring gepubliceerd (Thomaes \& Marchand, 2019) waarnaar verwezen wordt. 


\section{ROESTBRUINE KNIPTOR}

Voor de Roestbruine kniptor moet eerst de inhaalslag verder afgewerkt worden. Eenmaal de inhaalslag is afgerond en de verspreiding in kaart gebracht is, kan op basis hiervan een meetnet opgesteld worden. We stellen eerst in detail de inhaalslag voor en geven daarna alvast een beschrijving van het nog op te starten meetnet.

\subsection{INHAALSLAG MET FEROMOONONDALLEN}

De tekst uit versie 1.0 (onder doelstelling en algemene werkwijze) werd geüpdatet tot onderstaande tekst.

De inhaalslag voor deze soort werd opgestart in 2017 maar kon de eerste 2 jaren nauwelijks uitgevoerd worden door een gebrek aan goed werkende feromonen. Sinds 2019 beschikken we over goed werkende feromonen die het INBO in eigen opdracht laten produceren waardoor we ook in de toekomst verzekerd zijn van een kwalitatieve aanlevering van feromonen. In 2018 en 2019 werden een aantal onderzoeken uitgevoerd die meer inzicht geven in de fenologie en inzet van vallen. In 2018 testen we of we rubberen septa konden gebruiken in plaats van eppendorfjes die door de vrijwilliger verdere behandeling vragen. Uit het onderzoek bleek een gelijkaardig resultaat van beide materialen. In 2019 werd een onderzoek gedaan naar het effect van het valtype (vergelijking tussen een eenvoudige flessenval en een grote val bestaande uit 16 trechters). Verder keken we naar de fenologie van de kever en de tijdsinspanning die nodig is om de soort vast te stellen (detectie) en de trend te monitoren. Hiervoor werden in 5 gebieden en 4 locaties per gebied een van beide vallen getest. Ook zijn er van een aantal plaatsen nieuwe verspreidingsgegevens die meegenomen werden om de locaties voor de inhaalslag te bepalen.

\subsubsection{Selectie en prioritering van te onderzoeken hokken}

De oefening van de te onderzoeken hokken (UTM $1 * 1 \mathrm{~km}$ ) uit Thomaes et al. (2016a) werd herdaan op basis van recente verspreidingsgegevens ( 51 gekende vindplaatsen en 9 onderzochte afwezigheden). Doelstelling is om in elk ecodistrict 0,5\% van de hokken te onderzoeken. In de eerste plaats kijken we naar hokken waar de soort al gekend is en hokken die al voldoende onderzocht werden (nulwaarnemingen). Per ecodistrict worden deze hokken verder aangevuld met 'te onderzoeken hokken' tot het streefcijfer van 1,5\% bereikt wordt. Bij de selectie van deze hokken worden de hokken met het meeste leefgebied geselecteerd maar 
worden naast elkaar liggende hokken niet samen geselecteerd. In totaal blijven er 83 te onderzoeken gebieden over (Zie Figuur 4, Tabel 3).

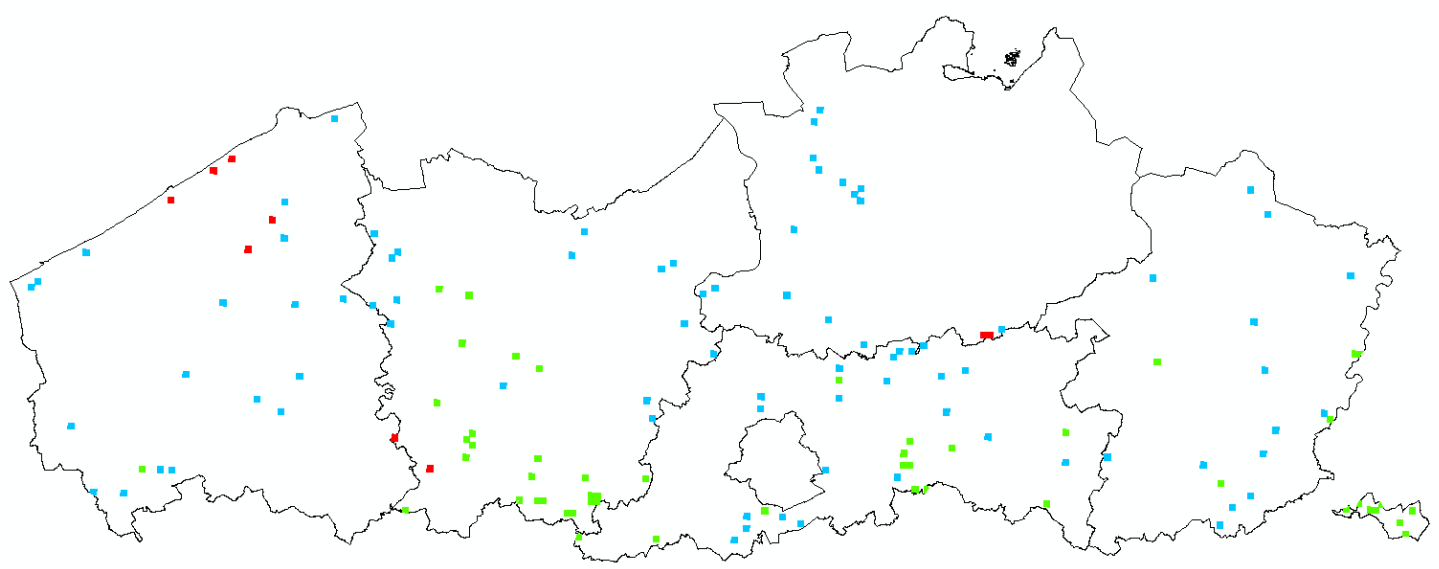

Figuur 4 Hokkenkaart (UTM 1*1 km) met de gekende vindplaatsen 2010-2019 (groen), bevestigde afwezigheden (rood) en te onderzoeken hokken (blauw)

\subsubsection{Veldprotocol}

Om een kilometerhok te onderzoeken wordt hierbinnen twee locaties geselecteerd met verschillende holle bomen (vaak knotbomen, hoogstamboomgaarden, oude parken of oude loofbossen). De feromoonvallen worden op die locaties minstens gedurende 6 dagen (of tot het vaststellen van de soort) opgehangen in juli bij geschikt weer (geen sterke wind of regen en dagtemperaturen van minstens $12^{\circ} \mathrm{C}$ ). Een feromoonval bestaat uit een lege petfles van 1 tot 2 liter waarvan de hals wordt afgesneden en omgekeerd op de fles wordt geplaatst. We bezorgen de vrijwilligers een rubberen blokje (septa) met de feromonen. Gezien we voor de inhaalslag enkel geïnteresseerd zijn in aan- of afwezigheid van de soort, kan de val onmiddellijk

Tabel 3 Lijst met te onderzoeken kilometerhokken voor de Roestbruine kniptor

\begin{tabular}{llll}
\hline $\begin{array}{l}\text { WestVlaanderen } \\
\text { Geselecteerd } \\
\text { hok }\end{array}$ & Naam & $\begin{array}{l}\text { Geselecteerd } \\
\text { hok }\end{array}$ & Naam \\
\hline DS8725 & Kemmel & ES0357 & Wijnendalebos \\
DS8225 & Vidaigneberg & ES0941 & Sterrebos \\
DS9529 & De Vlierlingen & ES1339 & Kasteel Bosmolens \\
DS9329 & Palingbeek2 & ES1368 & Tillegembos \\
DS7836 & De Lovie & ES1374 & Kasteel Norenburg \\
DS7159 & Calmeynbos & ES1557 & Lakebos \\
DS7260 & Houtsaegersduinen & ES1645 & 't Veld \\
DS8065 & Kartuizerduinen & ES2188 & Knokke-Heist \\
DS9745 & Bos van Houthulst2 & ES2358 & Sint-Pietersveld \\
\hline
\end{tabular}




\begin{tabular}{|c|c|c|c|}
\hline \multicolumn{4}{|c|}{ (vervolg Tabel 3) } \\
\hline \multicolumn{4}{|c|}{ Oost-Vlaanderen } \\
\hline $\begin{array}{l}\text { Geselecteerd } \\
\text { hok }\end{array}$ & Naam & $\begin{array}{l}\text { Geselecteerd } \\
\text { hok }\end{array}$ & Naam \\
\hline ES2857 & Aalter & ES6370 & Heidebos \\
\hline ES2869 & Kallekesbos & ES7442 & Overhamme \\
\hline ES3154 & Poeke & ES7539 & Wellemeersen \\
\hline ES3165 & Westvoorde & ES7664 & Waasmunster - Heide2 \\
\hline ES3258 & Loveld & ES7865 & Waasmunster - Heide3 \\
\hline ES3266 & Drongengoed & ES8055 & Vlassenbroekse polder \\
\hline ES5044 & Makegembos & ES8550 & Buggenhoutbos \\
\hline ES6166 & Puyenbroek & & \\
\hline \multicolumn{4}{|l|}{ Antwerpen } \\
\hline $\begin{array}{l}\text { Geselecteerd } \\
\text { hok }\end{array}$ & Naam & $\begin{array}{l}\text { Geselecteerd } \\
\text { hok }\end{array}$ & Naam \\
\hline ES8360 & Weert & FS0456 & Kasteel Kauwendaal \\
\hline ES8561 & Kasteel van Marnix1 & FS0679 & Schoten1 \\
\hline ES9760 & Bosstraat & FS0877 & Schilde3 \\
\hline ES9871 & Den Brandt2 & FS0976 & Schilde1 \\
\hline FS0183 & Mariaburg & FS0978 & Bellemont \\
\hline FS0189 & Kapellenbos1 & FS1052 & Rijmenam \\
\hline FS0281 & Eikendaal & FS3355 & Schriekem \\
\hline FS0291 & Kalmthout & & \\
\hline \multicolumn{4}{|c|}{ Vlaams-Brabant } \\
\hline $\begin{array}{l}\text { Geselecteerd } \\
\text { hok }\end{array}$ & Naam & $\begin{array}{l}\text { Geselecteerd } \\
\text { hok }\end{array}$ & Naam \\
\hline ES8919 & Essenbeek & FS1550 & Keerbergen4 \\
\hline ES9121 & Begijnenbos & FS1630 & Meerdaalwoud: Kouterbos \\
\hline ES9123 & Kesterbeek & FS1651 & Keerbergen2 \\
\hline ES9341 & Boechout & FS1851 & Kruisheide \\
\hline ES9343 & Meise3 & FS2052 & Vondelpark \\
\hline ES9723 & Zoniënwoud: west & FS2347 & Heikantberg \\
\hline FS0022 & Zoniënwoud: zuid & FS2441 & Chartreuzenbos \\
\hline FS0431 & Kasteel Les Bouleaux & FS2748 & 's Hertogenheide \\
\hline FS0643 & Hellebos & FS3137 & Kapellebos \\
\hline FS0648 & Schiplakenbos & FS4433 & Linter \\
\hline FS1446 & Kasteel de Spoelberch & & \\
\hline \multicolumn{4}{|l|}{ Limburg } \\
\hline $\begin{array}{l}\text { Geselecteerd } \\
\text { hok }\end{array}$ & Naam & $\begin{array}{l}\text { Geselecteerd } \\
\text { hok }\end{array}$ & Naam \\
\hline FS7023 & Lauw & FS8742 & Pietersheim \\
\hline FS7226 & Jekerbeemd & FS7749 & Bret1 \\
\hline FS7528 & De Kevie2 & FS7557 & Masy \\
\hline FS6733 & Opleeuw & FS5864 & Park Leopoldsburg \\
\hline FS5134 & Wartaardebos & FS9165 & Jagersborg \\
\hline FS7735 & Alden Biesen & FS7775 & Lozerheide \\
\hline FS7939 & Groenendaalbos & FS7479 & Warmbeekvallei2 \\
\hline
\end{tabular}


bezorgen de vrijwilligers een rubberen blokje (septa) met de feromonen. Gezien we voor de inhaalslag enkel geïnteresseerd zijn in aan- of afwezigheid van de soort, kan de val onmiddellijk verwijderd worden wanneer de soort wordt vastgesteld en moet ze dus niet steeds 6 dagen blijven hangen. Omdat de kever soms onmiddellijk reageert op de feromonen, is het interessant om 10 tot 15 minuten bij de val te blijven staan en te kijken of de kever waargenomen wordt. De mannetjes die door de feromonen worden aangetrokken vliegen doorgaans tijdens het warmste momenten van de dag. Meestal zal de kever rond de val beginnen vliegen of op de waarnemer landen. Een nulmeting van een hok bestaat uit minstens 3 vangstlocaties binnen het hok die 6 dagen opgevolgd werden (gelijktijdig of na elkaar).

\subsubsection{Gegevensinvoer}

De waarnemingen (inclusief nulwaarnemingen) worden ingevoerd in meetnetten.be. De teller geeft de exacte locatie(s) aan van de feromonenval(len) binnen het UTM hok, het aantal waargenomen individuen en de duur dat de feromonen opgehangen werden (bv. $15 \mathrm{~min}$ of 72u). Voor elke vangstsessie wordt ook de naam van de teller, de datum, de geschiktheid van de weersomstandigheden $\left(\geq 12^{\circ} \mathrm{C}\right)$ ingevoerd. Op deze manier kunnen gebieden waarbij minstens 3 locaties onderzocht werden en waar geen dieren gevonden werden, afgevinkt worden. De feromonen zijn soort specifiek en de kans is klein dat andere kniptorren in de vallen terecht komen waardoor foto's geen noodzaak zijn maar zeker een aanvullende waarde hebben. Foto's worden best geregistreerd via waarnemingen.be.

\subsection{MEETNET MET FEROMOONVALLEN}

$\mathrm{Na}$ het afronden van de inhaalslag, kunnen 30 locaties geselecteerd worden voor het meetnet.

\subsubsection{Veldprotocol}

Het plaatsen en opvolgen van de feromoonvallen is gelijkaardig aan de inhaalslag. Enkel worden de vallen iets langer opgevolgd zodat de kans groter is om meerdere individuen te vangen wat een monitoring in de tijd mogelijk maakt. We stellen voor om bij de monitoring 3 vallen te gebruiken en ze gedurende 12 dagen te laten hangen. De vallen worden om de 3 dagen gecontroleerd en de gevangen dieren worden vrijgelaten op minstens $100 \mathrm{~m}$ van de val.

\subsubsection{Selectie meetnetlocaties}

Voor Roestbruine kniptor gebruiken we een steekproeftrekking die pas kan uitgevoerd worden nadat de inhaalslag afgrond is. Hierbij zullen 30 gebieden geselecteerd worden om deel van het meetnet uit te maken. Ook hier zal een gestratificeerde aanpak gevolgd worden zodat in 
elke ecodistrict hokken worden geselecteerd a rato van de aanwezigheid van de soort in dat gebied. Van de 30 gebieden worden er elk jaar 10 onderzocht.

\subsubsection{Gegevensinvoer}

Gegevens worden op dezelfde manier ingevoerd als bij de inhaalslag.

\section{VLIEGEND HERT}

Na het uitvoeren van de inhaalslag van Vliegend hert hebben we voldoende zicht op de verspreiding van de soort. Daarom wordt de soort nu verder gemonitord via een meetnet. Er bestaat al een Europese samenwerking om dezelfde monitoringstechniek toe te passen in een aantal landen. Hiervoor is al een website en invoerportaal beschikbaar. Ook in Vlaanderen willen we deze standaard techniek verder blijven toepassen aangezien al een aantal Europese transecten al enkele jaren opgevolgd worden in Vlaanderen.

\subsection{MEETNET MET TRANSECTEN}

\subsubsection{Veldprotocol}

De transecttellingen voor het Vliegend hert zijn gebaseerd op een Europees protocol (www.stagbeetlemonitoring.org).

Het transect wordt bij voorkeur wekelijks gelopen, wanneer de weercondities geschikt zijn, in juni en juli. Vliegende herten zijn zelden actief bij temperaturen lager dan $12^{\circ} \mathrm{C}$ en worden volledig actief vanaf $18^{\circ} \mathrm{C}$. Daarom worden transect wandelingen bij voorkeur georganiseerd op warme $\left(>12^{\circ} \mathrm{C}\right)$ avonden met weinig of geen regen en geen sterke wind. Wanneer de temperatuur niet boven de $12^{\circ} \mathrm{C}$ stijgt gedurende één of meerdere weken, dan is er geen noodzaak om het transect af te gaan. Aangezien de fenologie van het Vliegend hert zich beperkt tot slechts enkele weken is het mogelijk om de eerste weken over te slaan wanneer er nog geen waarnemingen gebeurt zijn in Vlaanderen. De veldwerkcoördinator stuurt de vrijwilligers hierover aan.

Wanneer je op vakantie gaat of als er andere redenen zijn waardoor je het transect niet kan aflopen gedurende een bepaalde periode, is het aangewezen om een vervanger te hebben. Het transect zou minstens vijf keer per jaar gemonitord moeten worden. Extra transect wandelingen kunnen uitgevoerd worden geconcentreerd rond de korte activiteitspiek. Deze piek periode kan variëren tussen locaties en jaren maar neemt meestal plaats op het einde van juni of het begin van juli en wordt gekenmerkt door zwoele warme avonden. 
Het transect moet afgelopen worden van start tot einde met een trage constante wandelsnelheid zodat het 30 minuten duurt om het af te werken ( $83,3 \mathrm{~m}$ per 5 minuten). De transect wandeling dient 15 minuten voor zonsondergang te starten. Het transect wordt afgegaan door slechts één waarnemer die de observaties doet en ze noteert.

Noteer alle vliegende herten binnen een virtuele kooi van ongeveer $10 \mathrm{~m}$ voor de waarnemer en $5 \mathrm{~m}$ aan beide zijkanten van de waarnemer. Voor elke observatie noteer je het tijdstip, het aantal, het geslacht en de activiteit (vliegend/niet-vliegend/dood/parend). Verder vragen we om alle dode vliegende herten die je tegenkomt in te zamelen. Deze worden gebruikt voor genetische en morfometrische studies. Label de kevers en bewaar ze individueel, liefst in zuivere ethanol (zonder ether). INBO (arno.thomaes@inbo.be) voorziet de vrijwilligers van potjes en ethanol en zorgt voor de ophaling van de stalen.

\subsubsection{Selectie meetnetlocaties}

\subsubsection{Steekproefkader en -trekking}

Voor Vliegend hert wordt een integrale monitoring gedaan, d.w.z. dat alle locaties uit het steekproefkader worden opgevolgd. Er zijn populaties van de soort gekend uit $231 \times 1 \mathrm{~km}^{2}$ hokken. Voor al deze hokken, werd nagegaan of een transect kan geplaatst worden. Soms bestaat een hok grotendeels uit privé gronden waardoor geen transect van 500m kan ingetekend worden en verder zijn er locaties waar kleine relictpopulaties voorkomen (waar ondanks voldoende zoekinspanning niet jaarlijks Vliegende herten worden gevonden) waarbij de momenteel gekende methode van transecten onvoldoende is om de populatie te monitoren. Dit leverde in totaal 18 transecten op.

De ligging van de verschillende transecten is op $5 \times 5 \mathrm{~km}^{2}$-hok niveau voor iedereen zichtbaar op www.meetnetten.be. Details van de locaties zijn enkel zichtbaar voor mensen die aangemeld en aanvaard zijn bij het meetnet.

\subsubsection{Het uitzetten van een transect}

Gezien de beperkte verspreiding van deze soort werden in nagenoeg elk utm $1 * 1 \mathrm{~km}$ hok waar de soort voorkomt een potentieel transect ingetekend door het INBO. De doelstelling is om zoveel mogelijk van deze 18 transecten op te volgen. De transecten lopen langs openbare paden of wegen waar de soort regelmatig wordt waargenomen. Een transect is $500 \mathrm{~m}$ lang en ook de richting waarin het transect wordt afgelopen dient constant gehouden te worden. Bij voorkeur loop je het transect min of meer oostwaarts zodat de zon achter je onder gaat. 
Een transect wordt opgedeeld in 6 stukken ( $5 \mathrm{~min}$ per stuk, 83,3m). Door gebruik te maken van markeringen of opvallende punten op het transect kunnen de verschillende secties worden afgebakend zodat het transect gemakkelijk door anderen kan worden overgenomen.

\subsubsection{Gegevensinvoer}

De gegevens van transecttellingen voor het Vliegend hert worden ingegeven op stagbeetlemonitoring.org gezien het Europees kader. Vanaf 2020 zullen de invoerschermen aangestuurd worden vanuit observado.org waardoor ze de 'feel en look' en ook paswoorden hebben van andere observado producten. Op de website is ook een Nederlandstalige handleiding beschikbaar is voor de transectentellingen alsook Nederlandstalige veldformulieren.

De teller voert volgende zaken in: de datum, het uur van begin en einde van de telling en de weersomstandigheden genoteerd (temperatuur in ${ }^{\circ} \mathrm{C}$, windkracht in Beaufort en luchtvochtigheid in \%). Van elke waarneming wordt het tijdstip, het aantal, het geslacht en de activiteit genoteerd. Gebruik M (man), F (vrouw) of $U$ (onbekend) voor geslacht en DR (dood/resten), CO (parend), NF (niet-vliegend), FL (vliegend) en U (onbekend, niet genoteerd of veranderend tijdens observatie) voor activiteit.

\section{VERMILJOENKEVER}

\subsection{INHAALSLAG MET INVENTARISATIES VAN DODE BOMENيN}

Voor alle details van dit protocol wordt verwezen naar Thomaes \& Marchand (2019). Hieronder geven we de hoofdlijnen mee.

Vermiljoenkever werd in 2014 voor het eerst in Vlaanderen waargenomen en de soort is in de periode 2014-2019 al sterk uitgebreid. We vermoeden dat de soort ook in de komende jaren nog sterk zal uitbreiden waardoor een inhaalslag hier nodig is om deze uitbreiding op te volgen. Verder willen we via deze inhaalslag ook meer ervaring opdoen met deze soort.

\subsubsection{Selectie en prioritering van te onderzoeken hokken}

Voor de selectie van de op te volgen gebieden werd er per ecodistrict gewerkt waarbij voor elk ecodistrict $0,4 \%$ van de hokken werd geselecteerd met het hoogste leefgebied en met natuurgebied (domein beheerd door ANB of erkend reservaat). Dit laatste criterium is belangrijk omdat het huidig protocol destructief is voor de habitat en dus steeds toestemming 
van de eigenaar vereist is. De te onderzoeken hokken werden nadien in een gebiedsnaam omgezet (zie Tabel 4).

Er zijn in Vlaanderen slechts een beperkt aantal mensen actief bezig met het zoeken naar dood-houtkevers zoals deze soort. Ook valt te verwachten dat het moeilijk kan zijn om vrijwilligers voor dit protocol te overtuigen gezien het destructieve effect hoewel lokale conservators misschien nog wel te vinden zijn om deze soort in hun eigen gebied te zoeken. Om deze reden werden dan ook slechts $0,4 \%$ van de hokken geselecteerd. Verder werden deze hokken opgesplitst in 2 groepen, geselecteerde hokken die binnen het kader van deze inhaalslag als doel gesteld worden en aanvullende hokken die kunnen opgevolgd worden indien bijkomstige tijd beschikbaar is, bijvoorbeeld in het kader van stages of thesissen. Het aantal geselecteerde hokken komt daarom neer op 30 plaatsen die om de 3 jaar opgevolgd worden (10 per jaar). Aangezien de snelheid van uitbreiden niet gekend is, is het mogelijk dat ook na het derde jaar, verdere opvolging nodig is.

\subsubsection{Veldprotocol}

Voor elk te onderzoeken gebied worden vijf geschikte locaties/bestanden geselecteerd die op terrein onderzocht worden. Op elke locatie worden maximaal drie (gezien de destructieve zoekmethode) geschikte dode bomen onderzocht (dikke, recent gestorven bomen met een ruwe schors op vochtig tot natte standplaats). Het gaat om bomen die één tot drie jaar geleden gestorven zijn, nog het overgrote deel van hun schors hebben en waarbij de schors nog redelijk vast zit maar niet te vast. Onder de schors moet er een rode of donkerbruine verkleuring te vinden zijn die duidt op een vergistingsproces bij gebrek aan zuurstof. Zodra er een larve of kever gevonden wordt, wordt het onderzoek aan deze boom gestaakt en wordt een volgende boom onderzocht om zo de impact te minimaliseren. De larven zijn vooral in de winterperiode gemakkelijk te vinden. Voor het verwijderen van de schors van een boom is een klauwhamer het meest geschikt, verder is een lintmeter nodig om de omtrek en onderzochte oppervlakte op te meten. 


\begin{tabular}{|c|c|c|c|}
\hline $\begin{array}{l}\text { WestVlaander } \\
\text { Geselecteerd } \\
\text { hok }\end{array}$ & Naam & $\begin{array}{l}\text { Aanvullend } \\
\text { hok }\end{array}$ & Naam \\
\hline DS7631 & Helleketelbos (ANB) & DS7635 & Kasteel Couthof (privé) \\
\hline DS9429 & Palingbeek (provincie) & DS8435 & Galgebossen (ANB) \\
\hline DS9646 & Houthulst (ANB) & DS9127 & Kronaard (privé) \\
\hline ES0357 & Wijnendalebos (ANB) & ES0766 & Vloetemveld (ANB) \\
\hline \multirow[t]{3}{*}{ ES1740 } & Mandelhoek (natuurpunt) & ES1243 & Rodesgoed (ANB) \\
\hline & & ES2557 & Vorte bossen (Natuurpunt) \\
\hline & & ES2628 & Banhoutbos (privé) \\
\hline \multicolumn{4}{|c|}{ Oost-Vlaanderen } \\
\hline $\begin{array}{l}\text { Geselecteerd } \\
\text { hok }\end{array}$ & Naam & $\begin{array}{l}\text { Aanvullend } \\
\text { hok }\end{array}$ & Naam \\
\hline ES3366 & Drongengoed (Defensie/ANB) & ES2869 & Kallekesbos (privé) \\
\hline ES3154 & Kasteel van Poeke (ANB) & ES3635 & Hof te Walem (privé) \\
\hline ES3968 & Het Leen (provincie) & ES4128 & Koppenbergbos (ANB) \\
\hline ES4533 & Bos 't Ename (Natuurpunt) & ES5024 & Brakelbos (ANB) \\
\hline ES6628 & De Nuchten (ANB) & ES6166 & Puienbroek (provincie) \\
\hline ES6969 & Heirnisse (ANB) & ES8055 & $\begin{array}{l}\text { Vlassenbroekse polder } \\
\text { (Natuurpunt) }\end{array}$ \\
\hline ES8254 & Grote Wal (Natuurpunt) & ES8550 & Buggenhoutbos (ANB) \\
\hline ES3423 & Kluisbos (ANB) & & \\
\hline \multicolumn{4}{|l|}{ Antwerpen } \\
\hline $\begin{array}{l}\text { Geselecteerd } \\
\text { hok }\end{array}$ & Naam & $\begin{array}{l}\text { Aanvullend } \\
\text { hok }\end{array}$ & Naam \\
\hline ES8561 & Kasteel van Marnix (privé) & ES9271 & Fort van Kruibeke (Defensie) \\
\hline ES9576 & $\begin{array}{l}\text { St-Annabos (ANB) } \\
\text { Broek De Naeyer (provincie) }\end{array}$ & ES9359 & Polders van Bree (ANB) \\
\hline ES9659 & Biezeweiden (Natuurpunt) & FS3791 & Ravels (ANB) \\
\hline FS2458 & Grote Nete (ANB/Natuurpunt) & & \\
\hline FS2587 & $\begin{array}{l}\text { Eksterheide (ANB) } \\
\text { Vrieselhof (provincie), Schiinvallei }\end{array}$ & & \\
\hline FS1175 & (Natuurpunt) & & \\
\hline FS5277 & De Maat (Natuurpunt) & & \\
\hline \multicolumn{4}{|c|}{ Vlaams-Brabant } \\
\hline $\begin{array}{l}\text { Geselecteerd } \\
\text { hok }\end{array}$ & Naam & $\begin{array}{l}\text { Aanvullend } \\
\text { hok }\end{array}$ & Naam \\
\hline ES8138 & 'Overnelle' (ANB) & ES8143 & Kravaalbos (ANB) \\
\hline ES9226 & Calmeyn (privé) & FS0643 & Hellebos (Natuurpunt) \\
\hline FS1529 & Doode Bemde (ANB) & FS1633 & Doode Bemde (ANB) \\
\hline & De Gevel (ANB) Wijgmaalbroek & & \\
\hline FS2044 & (Natuurpunt) & FS2353 & $\begin{array}{l}\text { Meren/Meerloop (privé) } \\
\text { Molenstedebroek/Demervallei }\end{array}$ \\
\hline FS3551 & Demerbroeken (Natuurpunt) & FS4051 & (ANB) \\
\hline FS4735 & Terhagen (privé) & FS4438 & Tienbunders (privé) \\
\hline
\end{tabular}




\begin{tabular}{|c|c|c|c|}
\hline $\begin{array}{l}\text { (vervolg Tabel } 4 \\
\text { Limburg } \\
\text { Geselecteerd } \\
\text { hok }\end{array}$ & Naam & $\begin{array}{l}\text { Aanvullend } \\
\text { hok }\end{array}$ & Naam \\
\hline FS7226 & Jekervallei (ANB) & FS6069 & $\begin{array}{l}\text { Groite nete thv Pijnven (privé, } \\
\text { ANB) }\end{array}$ \\
\hline FS7663 & Vallei van de Abeek (Natuurpunt) & FS7528 & De Kevie (Natuurpunt) \\
\hline FS9052 & Het Greven (VMW) & FS7939 & Groenendaal (ANB) \\
\hline FS9165 & Jagersbos (ANB) & FS8845 & Daalbroek (privé) \\
\hline FS5752 & Melisbroek (ANB) & FS9771 & Het Vijverbroek (Natuurpunt) \\
\hline FS5960 & Vallei van de Zwarte Beek (Natuurpunt) & & \\
\hline FS6778 & Laukens Kapelleke (privé) & & \\
\hline FS6835 & Belle-Vuebos (ANB) & & \\
\hline FS7480 & Warmbeekvallei (ANB) & & \\
\hline GS0424 & Middelhof (privé) & & \\
\hline
\end{tabular}

\subsubsection{Gegevensinvoer}

De waarnemingen (inclusief nulwaarnemingen) worden gedocumenteerd via meetnetten.be. Op deze manier hebben we precieze info over locatie en aantallen. De waarnemer geeft de exacte locatie van de onderzochte bomen aan binnen het kilometerhok. Vervolgens voert hij voor elke onderzochte boom volgende zaken in: boomsoort, omtrek, en positie (staand, liggend, hangend), aantal gevonden larven/adulten en de onderzochte oppervlakte (benaderd als een ovaal met bepaalde lengte en breedte van het ontschorste deel). Dit laatste kan helpen om een betere zicht te krijgen op de lokale populatiegrootte. Foto's worden ingegeven in waarnemingen.be of bezorgt aan de meetnet coördinator.

\section{GEGEVENSINVOER}

\subsection{WATTE NOTEREN?}

\subsubsection{Feromoonvallen (voor inhaalslag of monitoring)}

Volgende gegevens worden genoteerd bij het opvolgen van de feromoonvallen: begindatum, exacte locatie binnen het UTM hok, het aantal waargenomen individuen en de duur dat de feromonen opgehangen werden. Verder wordt ook de geschiktheid van de weersomstandigheden $\left(\geq 12^{\circ} \mathrm{C}\right)$ ingevoerd. 


\subsubsection{Transecttellingen}

Volgende gegevens worden genoteerd bij elke transectwandeling: de datum, het uur van begin en einde van de telling en de weersomstandigheden genoteerd (temperatuur in ${ }^{\circ} \mathrm{C}$, windkracht in Beaufort en luchtvochtigheid in \%). Van elke waarneming wordt het tijdstip, het aantal, het geslacht en de activiteit genoteerd. Gebruik M (man), F (vrouw) of U (onbekend) voor geslacht en DR (dood/resten), CO (parend), NF (niet-vliegend), FL (vliegend) en U (onbekend, niet genoteerd of veranderend tijdens observatie) voor activiteit.

\subsubsection{Inventarisaties van dode bomen}

Per boom wordt coördinaten, het gebied, de waarnemer, boomsoort, omtrek en positie (staand, liggend hangend) van de boom opgelijst. Verder wordt het aantal gevonden larven/adulten en de onderzochte oppervlakte (benadert als een ovaal met bepaalde lengte en breedte van het ontschorste deel) geregistreerd.

\subsection{DE WEBAPPLICATIE}

Via de webapplicatie www.meetnetten.be kan de veldwerkcoördinator het veldwerk plannen en opvolgen. De vrijwilligers voeren daar ook hun tellingen in (voor Roestbruine kniptor en Vermiljoenkever) en maken bij voorkeur gebruik van de mobiele applicatie van www.meetnetten.be. Een handleiding voor het portaal en voor de mobiele applicatie is eveneens beschikbaar op deze website. Natuurpunt Studie stelt hier eveneens de "veldwerkhandleiding" per telprotocol ter beschikking. Dit is een praktische vertaling van de monitoringsprotocollen op maat van de tellers, waarin determinatietips en de invloed van soortecologie op de telmethode uitgelegd staat. Hier kan je eveneens handige telformulieren en geheugensteuntjes voor in het veld of voor tijdens de invoer terugvinden. 


\section{REFERENTIES}

Adriaens D., Westra T., Onkelinx T., Louette G., Bauwens D., Waterinckx M., Quataert P. (2011). Monitoring Natura 2000-soorten, Fase I: prioritering van de informatiebehoefte. Bosonderzoek I.v.N.-e., (editor). Brussel: Instituut voor Natuur- en Bosonderzoek. $136 \mathrm{p}$.

De Knijf G., Westra T., Onkelinx T., Quataert P., Pollet M. (2014). Monitoring Natura 2000-soorten en overige soorten prioritair voor het Vlaams beleid. Blauwdrukken soortenmonitoring in Vlaanderen. Bosonderzoek I.v.N.-e., (editor). Brussel: Instituut voor Natuur- en Bosonderzoek.

Herremans M., De Knijf G., Hansen K., Westra T., Vanreusel W., Martens E., Van Gossum H., Anselin A., Vermeersch G., Pollet M. (2014). Monitoring van beleidsrelevante soorten in Vlaanderen met inzet van vrijwilligers. Bosonderzoek I.v.N.-e., (editor). Brussel: Instituut voor Natuur- en Bosonderzoek.

Thomaes A., Maes D., Onkelinx T., Westra T., De Knijf G., Ledegen H. (2016a). Monitoringsprotocol kevers. Brussel: Instituut voor Natuur- en Bosonderzoek.

Thomaes A., Marchand S. (2019). Habitatrichtlijnsoort Vermiljoenkever (Cucujus cinnaberinus) als nieuwe soort in Vlaanderen. Brussel: Instituut voor Natuur- en Bosonderzoek.

Thomaes A., Marschand S. (2019). Habitatrichtlijnsoort Vermiljoenkever (Cucujus cinnaberinus) als nieuwe soort in Vlaanderen. Brussel: Instituut voor Natuur- en Bosonderzoek. $49 \mathrm{p}$.

Thomaes A., Pollet M., Vandekerkhove K. (2016b). Advies over de Vlaamse prioritaire soorten: voorstel tot aangepaste selectie van indicatorsoorten voor de functioneel-ecologische groep van doodhoutkevers. Brussels: Instituut voor Natuur- en Bosonderzoek. 19 p. 